\title{
The Mechanism of Action of LCZ696
}

\author{
Juan Tamargo Menendez
}

Department of Pharmacology, School of Medicine, University Complutense, Madrid, Spain

\begin{abstract}
Heart failure (HF) represents a growing financial burden on healthcare systems and despite therapeutic advances, mortality remains high. Current treatments focus on blocking neurohormonal pathways, such as the renin-angiotensin aldosterone system (RAAS). Recent research has focused on the natriuretic peptide system, which confers beneficial effects in HF, whereas activation of the RAAS and of the sympathetic nervous system has detrimental effects. LCZ696 (sacubutril/valsartan), a first-in-class angiotensin II AT ${ }^{1}$ receptor neprilysin inhibitor, has a unique mode of action that targets both pathways. Clinical studies to date indicate that LCZ696 is effective and safe in mild to moderate arterial hypertension and in HF patients with preserved ejection fraction, and has been shown to be superior to enalapril in patients with moderate to severe HF due to reduced left ventricular ejection fraction.
\end{abstract}

\section{Keywords}

Angiotensin receptor, neprilysin inhibitor heart failure, natriuretic peptides, LCZ696, neprilysin, renin-angiotensin-aldosterone system

Disclosure: The author has no conlicts of interest to declare.

Acknowledgement(s): This work was supported by grants from the Instituto de Salud Carlos III (PI11/01030 and Red de Investigación Cardiovascular-RIC, RD12/0042/0011) and Fundación BBVA. Medical Media Communications (Scientific) Ltd provided medical writing and editing support to the author, funded by Novartis Pharma AG.

Received: 27 January 2016 Accepted: 3 February 2016 Citation: Cardiac Failure Review, 2016;2(1):40-6 DOl: 10.15420/cfr.2016:1:1

Correspondence: Juan Tamargo Menendez, Department of Pharmacology, School of Medicine, University Complutense, 28040 Madrid, Spain. E: jtamargo@med.ucm.es

Chronic heart failure (HF) is a complex and progressive clinical syndrome resulting from any abnormality of cardiac structure or function. The American College of Cardiology Foundation/American Heart Association guideline defines HF as 'a complex clinical syndrome that results from any structural or functional impairment of ventricular filling or ejection of blood'." The European Society of Cardiology definition is 'an abnormality of cardiac structure or function leading to failure of the heart to deliver oxygen at a rate commensurate with the requirements of the metabolising tissues, despite normal filling pressures (or only at the expense of increased filling pressures). ${ }^{2}$

$\mathrm{HF}$ prevalence and the number of HF-related hospitalisations are increasing, and the prognosis remains poor, with a 5-year mortality worse than many cancers. ${ }^{3,4}$ There has been significant progress in HF therapy, but mostly in HF with reduced ejection fraction (HFrEF), while for patients with preserved ejection fraction (HFpEF), no therapy has improved clinical outcomes. ${ }^{2,5}$ Despite such advances, however, morbidity and mortality of HFrEF still remains high. It is evident, therefore, that substantial unmet needs exist in HF therapy. This article aims to review the mechanism of action and clinical development of sacubitril/valsartan (LCZ696), a first-in-class angiotensin receptor neprilysin inhibitor that has recently received regulatory approval in the US and Europe.

\section{The Role of the Renin-Angiotensin-Aldosterone System in Heart Failure}

Neurohumoral activation, in particular, of the renin-angiotensinaldosterone system (RAAS) and the sympathetic nervous system, plays a major role in the development and progression of HF., ${ }^{1,2}$ The RAAS is an essential component in the regulation of cardiovascular homeostasis that exerts its actions through the hormones angiotensin
II and aldosterone. The RAAS regulates vascular tone and blood pressure (BP) by means of vasoconstriction and renal sodium and water retention. ${ }^{\circ}$ Abnormalities in cardiac function in HF activate the RAAS and sympathetic nervous system in order to maintain perfusion of vital organs. ${ }^{7}$ However, prolonged activation of these systems increases systemic vascular resistance and causes sodium and water retention, myocardial hypertrophy, fibrosis and apoptosis, which accelerates the progression of $\mathrm{HF}$ and promotes end-organ damage. ${ }^{6,8-10}$

The blockade of beta-adrenergic receptors leads to symptomatic improvement and reduced morbidity and mortality in patients with HFrEF.9-13 In addition, the central role of the RAAS system in $\mathrm{HF}$ has led to the therapeutic use of RAAS inhibitors, ${ }^{2,8}$ including angiotensin-converting enzyme (ACE) inhibitors, ${ }^{14}$ angiotensin receptor blockers (ARBS) in patients who cannot tolerate ACE inhibitors ${ }^{15}$ and mineralocorticoid receptor antagonists in the treatment of chronic HF. 16,17 ARBS competitively inhibit the binding of angiotensin II to its AT, receptors located on blood vessels and other tissues, and improve symptoms, haemodynamics and outcomes in chronic HF.1,2 These beneficial effects are attributed to the inhibition of the deleterious effects of $A T_{1}$ receptor stimulation, i.e., vasoconstriction, $\mathrm{Na}+$ and water retention, aldosterone and vasopressin release, stimulation of sympathetic tone, inflammation, fibrosis and cell growth (see Figure 1).

However, ACE inhibitors, ARBS, aldosterone receptor antagonists and combinations of drugs in these classes are limited in their ability to fully inhibit the activity of the RAAS. ${ }^{6,18}$ Furthermore, ACE inhibitors and ARBs induce a reactive rise in plasma renin activity that may eventually surpass their RAAS-inhibitory effect, and plasma aldosterone levels remain elevated in a subset of patients despite therapy, a phenomenon 
known as aldosterone escape or aldosterone breakthrough. ${ }^{19}$ In addition, ARBs do not enhance bradykinin-mediated vasodilation and are considered less effective than ACE inhibitors. ${ }^{2}$

For the past 25 years, an add-on therapy approach to chronic HF has been used, beginning with diuretics, then adding ACE inhibitors (or ARBS) and beta blockers, followed by mineralocorticoid receptor antagonists. 13,20,21 Ivabradine, which reduces heart rate, is also approved as an add-on therapy in $\mathrm{HF}^{22}$ Nevertheless, morbidity and mortality remain high and there is, therefore, a need for new therapeutic targets in HF.

\section{Role of Natriuretic Peptides in Heart Failure}

While the activation of the RAAS and sympathetic nervous system is detrimental in $\mathrm{HF}$, other counter-regulatory pathways are activated in $\mathrm{HF}$, including the natriuretic peptide (NP) system (see Figure 2). The NP system consists of atrial (ANP), ${ }^{23}$ B-type (BNP) ${ }^{24}$ and C-type (CNP) NPS; these hormones regulate BP and fluid homeostasis. ${ }^{25-27}$ ANP is synthesised and secreted in atria, BNP is secreted from the ventricles in response to mechanical stretch and increased intracardiac volume/ pressure and CNP mostly originates from endothelial and renal cells and is secreted in response to endothelium-dependent agonists and pro-inflammatory cytokines. ${ }^{25,26,28}$ NPS activate three transmembrane receptors: natriuretic peptide receptor (NPR)-A, NPR-B and NPR-C.27 The binding of NPs to type A (NPR-A) and type B (NPR-B) receptors activates guanylate cyclase, increasing levels of the second messenger cyclic guanosine monophosphate (CGMP) and its effector molecule protein kinase G. This induces natriuresis, diuresis, vasodilation and inhibition of the RAAS system and the sympathetic nervous system, as well as antifibrotic, antiproliferative and antithrombotic effects (see Figure 2). ${ }^{25,26,28}$

A growing body of evidence suggests that hypertension and HF may be consequences of a dysregulated NP system and that patients with HF and hypertension may have a deficiency of biologically active NPS. ${ }^{28,29}$ NPR-C clears NP from the circulation through receptormediated internalisation and degradation. Urodilatin, a renally synthesised isoform of ANP, stimulates NPR-A located in the glomeruli and collecting ducts and promote $\mathrm{Na}+$ excretion. ${ }^{30}$

Another key component of the NP system is neprilysin (neutral endopeptidase 24.11), which catalyses the degradation of ANP, BNP and CNP as well as the degradation of bradykinin, adrenomedullin, endothelin-1, substance P and angiotensin II (see Figure 1). ${ }^{31}$ Neprilysin is a potentially useful therapeutic target in $\mathrm{HF}^{0.28}$ Inhibition of neprilysin increases the levels of NP, causing vasodilation and a reduction in extracellular fluid volume. Neprilysin does not hydrolyse N-terminal prohormone of brain NP (NT-proBNP), therefore the latter is a useful cardiac biomarker to assess therapeutic effect and prognosis in patients treated with neprilysin inhibitors. ${ }^{32}$

\section{Clinical Development of Vasopeptidase Inhibitors}

Augmentation of NPS by direct administration of these peptides is difficult because oral delivery is ineffective and parenteral delivery problematic. While nesiritide has been shown to produce a modest improvement in dyspnoea, it does not favourably affect clinical outcomes, decongestion or renal function ${ }^{33-35}$ and safety concerns have been raised. ${ }^{36,37}$ Blockade of NP breakdown by neprilysin inhibitors has, therefore, been investigated. ${ }^{38}$ Oral neprilysin inhibitors, such as candoxatril, produced clinical benefit in patients with chronic HF..$^{39,40}$ However, candoxatril has no effect on, or increases, systolic BP (SBP) in
Figure 1: The Role of the Natriuretic Peptides in Heart Failure

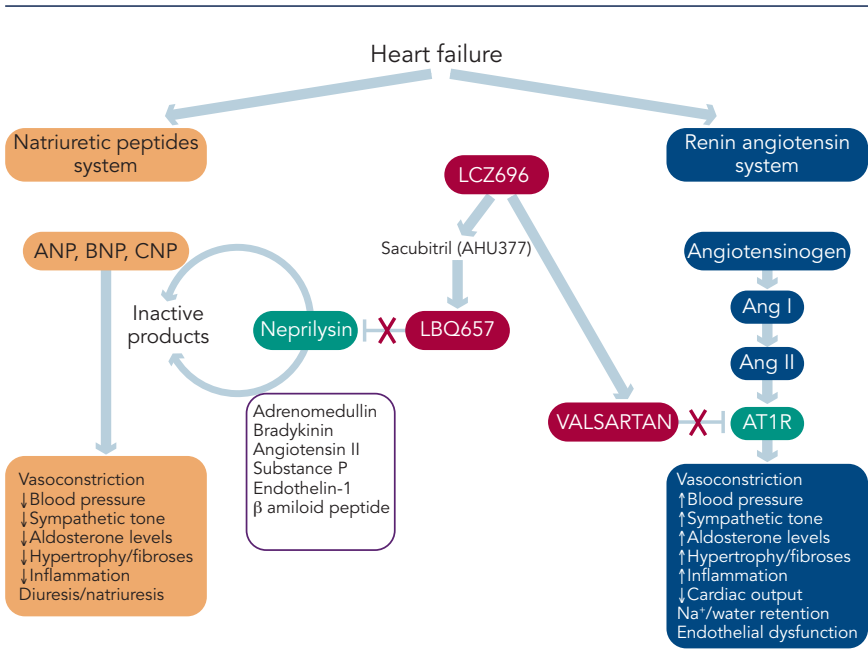

The natriuretic peptide (NP) system comprises three homologous peptides: atrial (ANP), brain (BNP) and C-type (CNP), and two biologically active receptors. ANP and BNP bind to the natriuretic receptor-A (NPR-A) and CNP specifically binds to the NPR-B. NPR-A and NRP-B are coupled to particulate forms of guanylyl cyclase (GC-A and GC-B) and catalyse the synthesis of cyclic guanosine (CGMP), which modulates the activity of CGMP-dependent protein kinase $G(P K G)$ to exert its multiple cardiac, vascular and renal actions. The NP-CGMP-PKG signalling pathway is terminated by phosphodiesterases (PDES) that hydrolyse CGMP to guanosine monophosphate (GMP). NPS are removed from the circulation and inactived by the clearance receptor (NPR-C) and degraded by several peptidases, including neprilysin (neutral clearance receptor (NPR-C) and degraded by several peptidases, including neprilysin (neut
endopeptidase) (NEP). In addition, the NPR-C mediates non-CGMP regulated biological actions. DAG: $=$ diacilglicerol; GTP = guanosine triphosphate; IP3 = inositol 1,4,5-trifosfato; $L T C C=L$-type calcium channel; $P L C=$ phospholypase $C ; R A A S=$ renin-angiotensinaldosterone system; UROD = urodilatin

Figure 2: Mechanism of Action of LCZ696 on Natriuretic Peptides

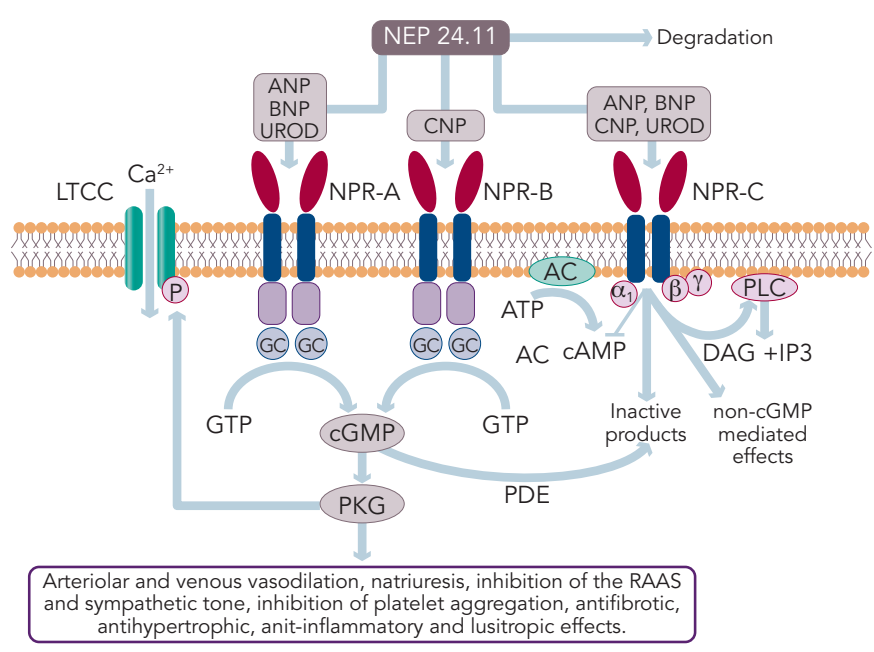

$A N P=$ atrial natriuretic peptide; $B N P=B$-type natriuretic peptide; $C N P=C$-type natriuretic peptide; $C G M P=$ cyclic guanosine monophospate; $D A G=$ diacilglicerol; $G C=$ guanylyl cyclase-A; GMP = guanosine monophosphate; GTP = guanosine triphosphate; IP3 = inosito 1,4,5-trifosfato; $L T C C=$ L-type calcium channel; NEP = neprilysin (neutral endopeptidase); $N P R=$ natriuretic peptide receptor; $P D E=$ phosphodiesterase; $P K G=$ protein kinase $G ;$ $P L C=$ phospholypase $C ; R A A S=$ renin-angiotensin-aldosterone system; UROD = urodilatin

normotensives, an effect prevented by enalapril, and does not reduce BP in hypertensive subjects, probably because its vasodilatory effect may be offset by an increased activity of the RAAS and sympathetic nervous system and/or by downregulation of NP receptors. ${ }^{41,42}$ In addition, since neprilysin acts on numerous physiological targets, the effect of candoxatril was broader than anticipated. ${ }^{41}$

Neprilysin inhibition results in activation of the RAAS, therefore, in order to be clinically beneficial, neprilysin inhibition requires concomitant inhibition of the RAAS. ${ }^{43}$ Vasopeptidase inhibitors are dual inhibitors of ACE and neprilysin and, therefore, emerged as a new therapeutic 


\begin{tabular}{|c|c|c|c|c|c|}
\hline $\begin{array}{l}\text { Authors/Trial } \\
\text { Name }\end{array}$ & Clinical Setting & $\begin{array}{l}\text { Trial } \\
\text { Description }\end{array}$ & Treatment & Primary Endpoint & Primary Outcomes \\
\hline PARADIGM-HF57 & $\begin{array}{l}\text { HFrEF: class II-IV, LVEF } \\
\leq 40 \% \text { (changed to } \leq 35 \% \text { ) } \\
\text { plasma BNP } \geq 150 \mathrm{pg} / \mathrm{ml} \\
\text { (N-terminal pro-BNP } \\
\geq 600 \mathrm{pg} / \mathrm{ml} \text { ) }\end{array}$ & $\begin{array}{l}\text { Phase III } \\
\text { R, DB, PG, ACS } \\
n=8,442 \\
\text { Follow-up } 27 \\
\text { months }\end{array}$ & $\begin{array}{l}\text { LCZ696 (200 mg twice } \\
\text { daily) or enalapril } \\
\text { (10 mg twice daily) }\end{array}$ & $\begin{array}{l}\text { Composite of } \mathrm{CV} \text { death or } \mathrm{HF} \\
\text { hospitalisation }\end{array}$ & $\begin{array}{l}\text { LCZ696 significantly reduced CV } \\
\text { or hospitalisation ( } 20 \% ; p<0.001) \text {, } \\
\text { CV death }(20 \%) \text { and all-cause } \\
\text { mortality }(16 \%) \text { versus enalapril }\end{array}$ \\
\hline TITRATION60 & $\begin{array}{l}\text { HFrEF (NYHA class II-IV, } \\
\text { LVEF } \leq 35 \% \text {, on beta } \\
\text { blockers) }\end{array}$ & $\begin{array}{l}\text { Phase I } \\
R, D B, P A \\
n=498\end{array}$ & $\begin{array}{l}\text { LCZ696: from } 50 \text { to } \\
200 \text { mg twice daily in a } \\
\text { 3-week (condensed) } \\
\text { versus 6-week } \\
\text { (conservative) regimen }\end{array}$ & $\begin{array}{l}\text { Proportion of patients } \\
\text { experiencing pre-specified } \\
\text { adverse events* and laboratory } \\
\text { outcomes including SBP }<95 \\
\text { mmHg and a doubling of serum } \\
\text { creatinine from baseline }\end{array}$ & $\begin{array}{l}\text { Treatment was successful in } \\
78 \% \text { and } 84 \% \text { of patients in the } \\
\text { condensed and conservative } \\
\text { regimens, respectively. The } \\
\text { target dose was achieved and } \\
\text { maintained for } 12 \text { weeks in } 76 \% \\
\text { of patients }\end{array}$ \\
\hline PARAMOUNT 61 & $\begin{array}{l}\text { HFpEF (LVEF } \geq 45 \%, \\
\text { NT-proBNP }>400 \text { pg/ml) }\end{array}$ & $\begin{array}{l}\text { Phase II } \\
D B, R, P G \\
n=301\end{array}$ & $\begin{array}{l}\text { LCZ696 (200 mg twice daily) } \\
\text { versus valsartan ( } 160 \mathrm{mg} \\
\text { twice daily) for } 36 \text { weeks }\end{array}$ & $\begin{array}{l}\text { Change in NT-proBNP from } \\
\text { baseline to } 12 \text { weeks }\end{array}$ & $\begin{array}{l}\text { At } 12 \text { weeks, NT-proBNP was } \\
\text { significantly reduced in the } \\
\text { LCZ696 group versus valsartan }\end{array}$ \\
\hline PARAGON-HF63 & $\begin{array}{l}\text { HFpEF (NYHA class II-IV, } \\
\text { LVEF >45 \%) }\end{array}$ & $\begin{array}{l}\text { Phase III } \\
R, D B, A C S \\
n=4,300\end{array}$ & $\begin{array}{l}\text { LCZ696 (50, } 100 \text { and } 200 \\
\text { mg) versus valsartan (40, } 80 \\
\text { and } 160 \mathrm{mg} \text { ) for up to } \\
57 \text { months }\end{array}$ & $\begin{array}{l}\text { Composite endpoint of CV } \\
\text { death and total (first and } \\
\text { recurrent) HF hospitalisations }\end{array}$ & Ongoing \\
\hline $\begin{array}{l}\text { UK HARP-III } \\
(\text { ISRCTN11958993) }\end{array}$ & $\begin{array}{l}\text { Proteinuric CKD (eGFR } \\
\geq 20<45 \mathrm{ml} / \mathrm{min} / 1.73 \mathrm{~m}^{2} ; \\
\text { or eGFR } \geq 45<60 \mathrm{ml} / \\
\mathrm{min} / 1.73 \mathrm{~m}^{2} \text { and urine } \\
\text { ACR } \geq 20 \mathrm{mg} / \mathrm{mmol})\end{array}$ & $\begin{array}{l}\text { Phase III } \\
R \\
n=360\end{array}$ & $\begin{array}{l}\text { LCZ696 (200, } 400 \text { mg once } \\
\text { daily) versus irbesartan } \\
(150,300 \mathrm{mg} \text { once daily) }\end{array}$ & $\begin{array}{l}\text { Difference in change in } \\
\text { measured eGFR from baseline } \\
\text { to } 6 \text { months }\end{array}$ & Ongoing \\
\hline Ruilope et al64 & $\begin{array}{l}\text { Mild-moderate } \\
\text { hypertension }\end{array}$ & $\begin{array}{l}\text { Phase III } \\
R, D B, P C, A C S \\
n=1,215\end{array}$ & $\begin{array}{l}\text { LCZ696 (100, 200, } 400 \mathrm{mg} \\
\text { once daily); valsartan } \\
\text { (80, 160, } 320 \mathrm{mg} \text { once } \\
\text { daily); AHU377 (200 mg } \\
\text { once daily) versus placebo }\end{array}$ & $\begin{array}{l}\text { Mean difference across the } \\
\text { three single-dose pairwise } \\
\text { comparisons of LCZ696 versus } \\
\text { valsartan in mean sitting DBP } \\
\text { at } 8 \text { weeks }\end{array}$ & $\begin{array}{l}\text { Significant reduction of SBP/ } \\
\text { DBP with LCZ696 } 200 \mathrm{mg} \text { and } \\
400 \mathrm{mg} \text { versus valsartan } 160 \\
\text { and } 320 \mathrm{mg} \text { Significant reduction } \\
\text { in ambulatory BP with LCZ696 } \\
\text { versus valsartan }\end{array}$ \\
\hline Kario et al65 & $\begin{array}{l}\text { Mild-moderate } \\
\text { hypertension (Asian } \\
\text { population) }\end{array}$ & $\begin{array}{l}\text { Phase III } \\
R, D B, P C \\
n=362\end{array}$ & $\begin{array}{l}\text { LCZ696 (100, } 200 \text { or } 400 \mathrm{mg} \\
\text { once daily) versus placebo } \\
\text { for } 8 \text { weeks }\end{array}$ & $\begin{array}{l}\text { Mean difference across the } \\
3 \text { single-dose pairwise } \\
\text { comparisons of LCZ696 versus } \\
\text { placebo in DBP }\end{array}$ & $\begin{array}{l}\text { Significant reductions in SBP/ } \\
\text { DBP, and pulse pressure with } \\
\text { LCZ696 versus placebo }\end{array}$ \\
\hline
\end{tabular}

*Symptomatic hypotension, hyperkalaemia, renal dysfunction, angioedema. $A C R=$ albumin:creatinine ratio; $A C S=$ active-controlled study; $B P=$ blood pressure; $C l=$ confidence interval; $C K D=$ chronic kidney disease; $C V=$ cardiovascular; $D B=$ double-blind; GFR = estimated glomerular filtration rate; HFrEF = heart failure with reduced ejection fraction; HFpEF = heart failure with preserved ejection fraction; $H R=$ hazard ratio; $L A=$ left atria; $L V=$ left ventricle; $L V E F=$ left ventricular ejection fraction; $N$-terminal pro-BNP = $N$-terminal prohormone of brain natriuretic peptide; NYHA = New York Heart Association; $P C=$ placebo-controlled; $P A=$ parallel assignment; $P G=$ parallel group; $R=$ randomised; $S B P / D B P=$ systolic/diastolic blood pressure.

option in HF and hypertension, but their pharmacological profile is complex. ${ }^{44}$ Omapatrilat was more effective than either lisinopril or amlodipine in reducing $\mathrm{BP}^{44}$ but in patients with chronic $\mathrm{HF}$ it was not more effective than enalapril in reducing the combined risk of death or hospitalisation for HF requiring intravenous treatment. ${ }^{45}$ However, omapatrilat was discontinued due to the risk of angioedema, possibly due to excessive inhibition of bradykinin degradation (presumably via neprilysin, ACE and aminopeptidase P). ${ }^{46,47}$

\section{Mechanism of Action of LCZ696}

Following the disappointing outcomes of combined ACE/neprilysin inhibition, the combination of neprilysin and an ARB was investigated. ARBs have a lesser effect on bradykinin ${ }^{48}$ and have been associated with lower risk of angioedema compared with ACE inhibitors, not significantly different from placebo..$^{49,50}$ Therefore, RAAS blockade at the $\mathrm{AT}_{1}$ receptor appears to be a preferable strategy to ACE inhibition. ${ }^{51}$ LCZ696 (Entresto'TM, Novartis) is a first-in-class angiotensin II receptorneprilysin inhibitor (ARNI) whose multimodal mode of action involves neprilysin inhibition and $\mathrm{AT}_{1}$ receptor blockade. LCZ696 is composed of two molecular moieties (in a 1:1 molar ratio) in a single crystalline complex comprising valsartan (an ARB) and sacubitril (AHU377). ${ }^{52}$ After ingestion, LCZ696 undergoes rapid dissociation into valsartan and sacubitril, a prodrug that is subsequently de-ethylated by esterases to LBQ657, a neprilysisn inhibitor.

In healthy volunteers, LCZ696 causes dose-dependent increases in ANP, plasma and urinary CGMP, renin concentration and activity and angiotensin II levels, as a result of neprilysin inhibition and $\mathrm{AT}_{1}$ receptor blockade (see Figure 1).52 After LCZ696 administration, levels of CGMP significantly increased at 4 and 12 hours and returned to baseline levels at 24 hours; all RAAS biomarkers reached a maximum after 4 hours and remained elevated at 24 hours. ${ }^{52}$ Thus, the pharmacodynamic effects of valsartan and LBQ657 are similar. In HF patients, levels of urinary CGMP, plasma BNP and renin concentration and activity were higher during treatment with LCZ696 than with enalapril, while circulating levels of markers of myocardial wall stress (N-terminal pro-BNP) and myocardial injury (troponin T) were lower during treatment with LCZ696 than with enalapril. ${ }^{53,54}$ After 21 days of LCZ696 administration (100 mg titrated to 
200 mg daily) a significant lowering of plasma NT-proBNP, aldosterone and endothelin-1 levels was observed. ${ }^{55}$

Nevertheless, the precise mechanism by which LCZ696 reduces cardiovascular mortality in HF patients is uncertain. ${ }^{56}$ The observed benefit is likely to be related to the incremental benefits of neprilysin inhibition, which may counteract the detrimental effects of RAAS and sympathetic nervous system activation. Other possible mechanisms might include: a haemodynamic improvement related to NP-mediated reduction in ventricular wall stress; an improvement in ventricular function; modification of the basis for fatal ventricular arrhythmias via decreased myocardial fibrosis and hypertrophy, attenuation of ventricular remodelling or direct anti-arrhythmic properties; sympatholytic or vagotonic effects of hormones potentiated by neprilysin inhibition; and anti-atherosclerotic or anti-thrombotic effects of enhanced NP expression leading to an improvement in regional myocardial perfusion. ${ }^{56}$ Further understanding of the mechanisms of action of LCZ696 would provide a deeper insight into the pathophysiology of HF and should be a priority in the future.

\section{Pharmacokinetic Properties of LCZ696}

Valsartan and LBQ657 have similar pharmacokinetic profiles, with rapid absorption, reaching maximum plasma concentrations within 1.5-4.5 hours, and a half-life of 8.9-16.6 and 9.9-11.1 hours, respectively, indicating that both agents exhibit comparable pharmacokinetic properties and that LCZ696 was suitable for once- or twice-daily dosing. ${ }^{52}$ Sacubitril (AHU377) reaches peak plasma levels within 0.5-1.1 hours and presents a half-life of 1.1-3.6 hours owing to its rapid conversion into the active metabolite LBQ657, which explains the rapid onset of activity of LCZ696. LCZ696 achieves $90 \%$ inhibition of neprilysin. ${ }^{52}$ Importantly, LCZ696 does not inhibit aminopeptidase A, unlike omapatrilat, thus minimising the risk of angiodema. ${ }^{52}$ In healthy volunteers, LCZ696 $400 \mathrm{mg}$ and valsartan $320 \mathrm{mg}$ provide similar exposure to valsartan.

\section{Clinical Development of LCZ696}

\section{Heart Failure}

The main clinical trials investigating the efficacy and safety of LCZ696 are summarised in Table 1. The pivotal clinical trial in the development of LCZ696 was the Prospective comparison of ARNI with ACEI to Determine Impact on. Global Mortality and morbidity in Heart Failure (PARADIGM-HF) study, which recruited patients $(n=8,442)$ with chronic HF (New York Heart Association [NYHA] class II-IV) and reduced left ventricular ejection fraction (LVEF; $\leq 40 \%$ to $\leq 35 \%$ ). ${ }^{57}$ The trial began with a single-blind run-in period to test drug tolerability. Patients received enalapril $10 \mathrm{mg}$ twice daily for 2 weeks, then 100 mg LCZ696 twice daily for 1-2 weeks and then 200 mg twice daily for 2-4 weeks. Two brief (one day) washout periods were also included to minimise the potential risk of angioedema due to overlapping ACE and neprilysin inhibition. During the run-in period, $12 \%$ of patients withdrew due to an adverse event. Following the run-in period, patients underwent double-blind 1:1 randomisation to LCZ696 $200 \mathrm{mg}$ twice daily or enalapril $10 \mathrm{mg}$ twice daily. Exclusion criteria included symptomatic hypotension (SBP $<100 \mathrm{mmHg}$ ) (at screening or $95 \mathrm{mmHg}$ at randomisation), an estimated glomerular filtration rate (eGFR) $<30 \mathrm{ml} / \mathrm{min} / 1.73 \mathrm{~m}^{2}$ at screening or at randomisation or a decrease in the eGFR $>25 \%$ (which was amended to $35 \%$ ) between screening and randomisation, a serum $\mathrm{K}+$ level $>5.2 \mathrm{mmol} / \mathrm{L}$ at screening (or $>5.4 \mathrm{mmol} / \mathrm{L}$ at randomisation) or a history of angioedema or unacceptable side effects during ACE inhibitor or ARB therapy.
Figure 3: Kaplan-Meier Curve for Primary Study Endpoint of PARADIGM-HF (Composite of Death from Cardiovascular Causes or First Hospitalisation for Heart Failure)

Primary endpoint

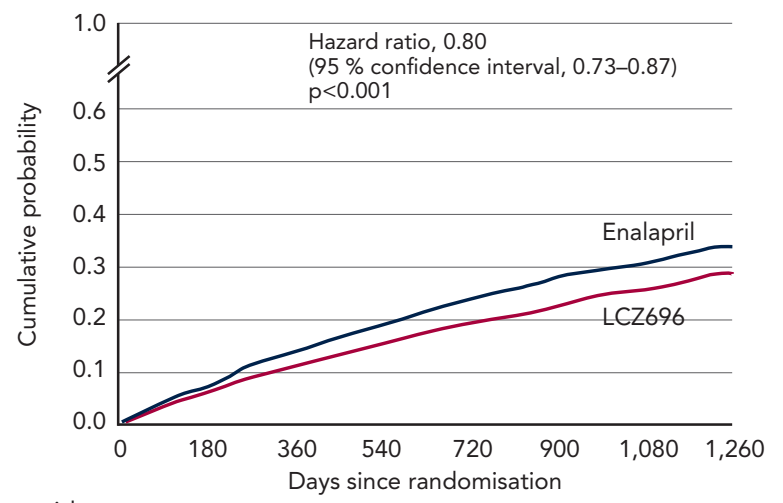

Number at risk

$\begin{array}{lllllllll}\text { LCZ696 } & 4,187 & 3,922 & 3,663 & 3,018 & 2,257 & 1,544 & 896 & 249\end{array}$

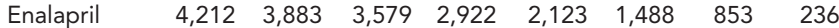

The natriuretic peptide (NP) system comprises three homologous peptides: atrial (ANP), brain (BNP) and C-type (CNP), and two biologically active receptors. ANP and BNP bind to the natriuretic receptor-A (NPR-A) and CNP specifically binds to the NPR-B. NPR-A and NRP-B are coupled to particulate forms of guanylyl cyclase (GC-A and GC-B) and catalyse the synthesis of cyclic guanosine (CGMP), which modulates the activity of CGMP-dependent protein kinase G (PKG) to exert its multiple cardiac vascular and renal actions. The NP-CGMPTGMP to guanosine monophosphate (GMP). NPS are removed from the circulation and inactived by the clearance receptor (NPR-C) and degraded by several peptidases, including neprilysin (neutral endopeptidase) (NEP). In addition, the NPR-C mediates non-CGMP regulated biological actions. DAG: = diacilglicerol; GTP = guanosine triphosphate; IP3 = inositol 1,4,5-trifosfato; LTCC = L-type calcium channel; $P L C$ = phospholypase C; RAAS = renin-angiotensin-aldosterone system; $U R O D=$ urodilatin. From MCMurray et al., Angiotensin-neprilysin inhibition versus enalapril in heart failure. N Engl I Med 2014:371(11): 993-1004. Copyright @ (2014) Massachusetts Medical Society. Reprinted with permission from Massachusetts Medical Society.

The trial was terminated early after a median follow up of 27 months due to evidence of an overwhelming benefit with LCZ696. The primary endpoint, a composite of death from cardiovascular causes or hospitalisation for HF, occurred in $21.8 \%$ of the LCZ696 group and 26.5 $\%$ of the enalapril group (hazard ratio [HR] in the LCZ696 group, 0.80; 95 $\%$ confidence interval $[\mathrm{CI}], 0.73-0.87 ; \mathrm{p}<0.001$ ) (see Figure 3). During the trial, the numbers of patients who would need to have been treated to prevent one primary event and one cardiovascular death were 21 and 32 , respectively. Death from any cause was reported in $17 \%$ of patients receiving LCZ696 and $19.8 \%$ receiving enalapril (HR 0.84; $95 \% \mathrm{Cl}$ 0.76-0.93; $p<0.001$ ); of these $13.3 \%$ and $16.5 \%$, respectively, died from cardiovascular causes (HR 0.80; $95 \% \mathrm{Cl} 0.71-0.89 ; \mathrm{p}<0.001) .{ }^{57}$ Using actuarial estimates from the PARADIGM-HF trial, and assuming that the protective effects of LCZ696 are sustained during long-term use, it has been estimated that treatment with LCZ696 could result in 1 to 2 years of increased life expectancy in patients with HF. ${ }^{58}$ LCZ696 also reduced the risk of hospitalisation for HF by $21 \%$ compared with enalapril $(p<0.001)$ and decreased HF symptoms $(p=0.001) .{ }^{57}$ Interestingly, these benefits were also observed in 2,907 patients with diabetes. In a sub-analysis of PARADIGM-HF, the benefit of LCZ696 compared with enalapril was consistent, regardless of glycaemia status. ${ }^{59}$

In addition, two recent analyses have focused on the effect of LCZ696 on the risk of clinical deterioration. A subanalysis of PARADIGM-HF focused on pre-specified measures of non-fatal clinical deterioration. ${ }^{53}$ Compared with enalapril, fewer patients in the LCZ696 group required treatment intensification for HF (520 versus 604; HR 0.84; $95 \% \mathrm{Cl}$ $0.74-0.94 ; \mathrm{p}=0.003$ ) or an emergency department visit for worsening HF (HR 0.66; $95 \% \mathrm{Cl} 0.52-0.85 ; \mathrm{p}=0.001$ ). Patients receiving LCZ696 had $23 \%$ fewer hospitalisations for worsening HF (851 versus 1,079; $95 \% \mathrm{Cl} 0.67-0.85 ; \mathrm{p}<0.001$ ) and $18 \%$ fewer stays in intensive care 
(768 versus 879; $p=0.005$ ), and were $31 \%$ less likely to receive intravenous positive inotropic agents $(p<0.001)$ and $22 \%$ less likely to have cardiac transplantation or implantation of a cardiac device for $\mathrm{HF}(\mathrm{p}=0.07)$. The reduction in hospitalisation was noted within the first 30 days after randomisation. Worsening symptoms were consistently more commonly reported in the enalapril group. ${ }^{53}$

Another analysis focused on the mode of death in the PARADIGMHF trial. The majority of deaths were cardiovascular (80.9\%), and treatment with LCZ696 significantly reduced the risk of cardiovascular death (HR 0.80; $95 \% \mathrm{Cl} 0.72-0.89 ; \mathrm{p}<0.001$ ). This reduced risk was primarily due to a reduction in both sudden cardiac death (HR 0.80; $95 \% \mathrm{Cl} 0.68-0.94 ; \mathrm{p}=0.008$ ) and death due to worsening HF (HR 0.79; $95 \% \mathrm{Cl} 0.64-0.98 ; \mathrm{p}=0.034)$. The treatment effect on sudden cardiac death was not affected by the presence or absence of an implantable cardioverter-defibrillator. ${ }^{56}$ Of note, LCZ696 reduced cardiovascular death to a similar extent as its reduction of HF hospitalisation, while the results of many pivotal studies of RAAS in HF found a more pronounced reduction in hospitalisations for worsening HF than cardiovascular death. ${ }^{56}$

The Safety and Tolerability of Initiating LCZ696 in Heart Failure Patients (TITRATION) study demonstrated the safety and efficacy of up-titrating LCZ696 from $50 \mathrm{mg}$ twice daily to a target dose of $200 \mathrm{mg}$ twice daily in a 3- (condensed) versus 6-week (conservative) regimen in patients with HFrEF ( $E F \leq 35 \%$ ) on beta-blockers. The study enrolled a broader range of patients than PARADIGM-HF, including inpatients and patients naïve to ACE inhibitors or ARBS. ${ }^{60}$ The study involved an open-label run-in period in which LCZ696 was tested for tolerability and safety at a $50 \mathrm{mg}$ twice daily for 5 days. Patients were then randomised to up-titration of LCZ696 to $200 \mathrm{mg}$ during the next 3 (condensed) or 6 weeks (conservative) regimen. Primary endpoints included the proportion of patients experiencing pre-specified adverse events (symptomatic hypotension, hyperkalaemia, renal dysfunction, angioedema) and outcomes including SBP $<95 \mathrm{mmHg}$ and a doubling of serum creatinine from baseline. In the primary endpoint of tolerability, there were no differences between groups. Treatment was successful in $78 \%$ and $84 \%$ of patients in the condensed and conservative regimens, respectively $(p=0.07)$. The target dose was achieved and maintained for 12 weeks in $76 \%$ of patients. The study also suggested that patients on ACE inhibitors or ARBs should probably be moved less quickly to up-titration of LCZ696.

There is a lack of effective treatments for patients with HFpEF, therefore LCZ696 was evaluated in this treatment setting. Prospective comparison of ARNI with ARB on Management Of heart failUre with preserved ejectioN fraction (PARAMOUNT) was a phase II study in patients with NYHA class II-III HF and LVEF $\geq 45 \%$. Participants $(n=301)$ were randomised to LCZ696 (titrated to $200 \mathrm{mg}$ twice daily) or valsartan (titrated to $160 \mathrm{mg}$ twice daily). The primary endpoint was change in NT-proBNP, a marker of left ventricular wall stress. ${ }^{61}$ At 12 weeks, NT-proBNP was significantly reduced in the LCZ696 group compared with the valsartan group (from $783 \mathrm{pg} / \mathrm{ml}$ to $605 \mathrm{pg} / \mathrm{ml}$ in the LCZ696 group versus from $862 \mathrm{pg} / \mathrm{ml}$ to $835 \mathrm{pg} / \mathrm{ml}$ in the valsartan group; ratio LCZ696:valsartan, 0.77; $95 \% \mathrm{Cl}$ 0.64-0.92; $p=0.005$ ). In addition, after 36 weeks more patients in the LCZ696 group showed improvements in NYHA functional class and reduced left atrial size compared with valsartan, consistent with reverse left atrial remodelling. LCZ696 was well tolerated with adverse effects similar to those of valsartan. A recently reported analysis from this study investigated the effects of LCZ696 on renal function in patients with
HFpEF. Treatment with LCZ696 for 36 weeks resulted in lower serum creatinine, higher eGFR and an increase in urinary albumin to creatinine ratio compared with valsartan. ${ }^{62}$

Although the PARAMOUNT study was not powered to detect clinical outcomes, it was a hypothesis-generating trial that provided the basis for the ongoing phase III Prospective comparison of Angiotensin Receptor neprilysin inhibitors with Angiotensin converting enzyme inhibitors to Determine Impact on Global Mortality and morbidity in Heart Failure (PARAGON-HF) trial, which aims to enrol 4,300 patients. Enrolment criteria are symptomatic HFpEF, NYHA class II-IV, LVEF $\geq 45 \%$ requiring treatment with diuretics for $\mathrm{HF} \geq 30$ days prior to study entry, structural heart disease (left atrial enlargement or left ventricular hypertrophy) documented by echocardiogram, a HF hospitalisation within 9 months prior to study entry and/or an elevated NT-proBNP.63 The primary endpoint is a composite of cardiovascular death and total HF hospitalisations. The treatment arm with the lower rate of events will be deemed to have the most successful response.

\section{Arterial Hypertension}

LCZ696 has also shown efficacy in clinical studies of hypertension. In a multinational study with sites in 18 countries, patients $(n=1,328)$ with mild-to-moderate hypertension were randomised to 8 weeks' treatment with LCZ696 (100, 200 or 400 mg daily), valsartan (80, 160 or 320 mg daily), sacubitril (200 mg daily) or placebo. ${ }^{64}$ The reduction in mean resting SBP and diastolic BP (DBP) was significantly greater for $200 \mathrm{mg}$ LCZ696 versus $160 \mathrm{mg}$ valsartan $(-11 /-6.1$ versus $-5.7 /-3.2 \mathrm{mmHg} ; \mathrm{p}<0.001)$ and for $400 \mathrm{mg}$ LCZ696 versus $320 \mathrm{mg}$ valsartan (-12.5/-6.9 versus $-6.4 / 4.1$ $\mathrm{mmHg} ; \mathrm{p}<0.005) .64$ Response rates were also significantly higher in patients on $200 \mathrm{mg}$ LCZ696 versus $160 \mathrm{mg}$ valsartan (91/163, 56 \%; $\mathrm{p}=0.0095)$, and on $400 \mathrm{mg}$ LCZ696 versus $320 \mathrm{mg}$ valsartan (103/163, $63 \%$; $\mathrm{p}=0.026$ ). No differences were found between $100 \mathrm{mg}$ LCZ696 and $80 \mathrm{mg}$ valsartan. In a multicentre study carried out in Japan, China, South Korea, Taiwan and Thailand, patients aged $\geq 18$ years $(n=389)$ with hypertension were randomised to LCZ696 (100, 200 or 400 mg once daily once daily) or placebo ( $n=92)$ for 8 weeks. Reductions in SBP, DBP $(p<0.0001)$ and pulse pressure $(p<0.001)$ were significantly greater with all doses of LCZ696 than with placebo. The reductions are greater than those observed in white European populations, as this Asian population has a higher salt intake and increased salt sensitivity. There were also significant reductions in 24-hour, daytime and nighttime ambulatory SBP, DBP and pulse pressure for all doses of LCZ696 compared with placebo $(p<0.0001) .^{65}$ Although the mechanism is uncertain, this effect can be related to its vascular effects and/or to reduced effective circulating volume. In the PARAMOUNT trial the reduction from baseline in mean SBP/DBP was -9.3/-4.9 mmHg with LCZ699 (200 mg twice daily) and -2.9/-2.1 mmHg with valsartan (160 mg twice daily)..$^{61}$ In the PARADIGMHF trial where $71 \%$ of patients had hypertension, LCZ696 therapy resulted in a significant reduction in SBP compared with enalapril (mean difference $-2.7 \mathrm{mmHg} ; \mathrm{p}<0.001$ ) over a period of 3 years. The role of the reduction in SBP on the decreased rate of death and $\mathrm{HF}$ hospitalisation observed in this trial is uncertain.

\section{Safety Profile of LCZ696}

In clinical studies of hypertension, LCZ696 was well-tolerated and no cases of angioedema or deaths were reported. The most common adverse events were headache and pruritus, ${ }^{64}$ nasopharyngitis and upper respiratory tract infection. ${ }^{64,65}$ Hypotension or syncope occurred in five patients (one each in the placebo, $400 \mathrm{mg}$ LCZ696 and $200 \mathrm{mg}$ AHU377 groups; two in the 200 mg LCZ696 group). ${ }^{64}$ Adverse events 
resulting in treatment discontinuation occurred in 1-2 \% of patients on LCZ696, with the highest occurrence in the AHU377 and placebo groups. ${ }^{64}$ However, patients with diabetes and renal disease (eGFR $>30 \mathrm{ml} / \mathrm{min} / 1.73 \mathrm{~m}^{2}$ ) were excluded from these trials.

In the PARADIGM-HF study, $12 \%$ of patients did not complete the run-in period because of adverse events, most frequently cough, hyperkalaemia, renal dysfunction or hypotension. Across the study period, LCZ696 was discontinued in 746 patients (17.8 \%) and enalapril in 833 patients (19.8\%). During the double-blind phase, the LCZ696 group had higher rates of hypotension $(p<0.001)$ and non-serious angioedema $(p=0.31)$, but significantly lower rates of serum creatinine $\geq 2.5 \mathrm{mg} / \mathrm{dl}$, serum potassium $\geq 6 \mathrm{mmol} / \mathrm{L}$ and cough than the enalapril group, and a lower overall incidence of adverse events. Fewer patients in the LCZ696 group than in the enalapril group stopped drug medication because of an adverse event (10.7\% versus $12.3 \%$; $\mathrm{p}=0.03$ ) or renal impairment (0.7 \% versus $1.4 \% ; \mathrm{p}=0.002) .{ }^{57}$ In the PARAMOUNT trial the number of patients with hypotension, renal dysfunction or hyperkalemia did not differ between groups. ${ }^{61}$

However, questions remain regarding the safety of LCZ696. Although it is better tolerated than valsartan in clinical studies, it showed a higher incidence of hypotension, an important consideration in elderly patients, although this rarely resulted in discontinuation of treatment, and the number of discontinuations due to hypotension were balanced across both groups. In addition, the question of angioedema in daily clinical practice remains unanswered. Angioedema is more common in patients of African origin, ${ }^{66,67}$ but these were under-represented in the PARADIGM-HF (5\%). There is also a need for studies in ACE inhibitornaïve patients, where benefits were less pronounced in PARADIGM-HF, although it should be noted that all patients had an enalapril run-in phase so were not truly naïve.

A recent review paper discussing preclinical models and human genetic analyses suggested that neprilysin inhibitors may lead to an accumulation of amyloid beta-peptide in the brain and may thus accelerate Alzheimer's disease progression in at-risk patients. ${ }^{68}$ This is a hypothetical concern and not based on any human studies: a Chinese study found no association between two NEP gene polymorphisms and Alzheimer's disease in elderly people. ${ }^{69}$ Furthermore, a 2-week LCZ696 administration in human healthy volunteers did not modify Abeta $_{1-40}$ and Abeta $_{1-42}$ levels in the cerebrospinal fluid ${ }^{70}$ and no cognition-related adverse events related to treatment have been reported in any of the randomised clinical trials to date, probably because multiple (20) proteins are involved in the clearance of amyloid beta-peptides. There is therefore no conclusive evidence for an association between NEP and Alzheimer's disease in humans. Cognition-related adverse effects were observed in the PARADIGM-HF trial, as expected in a study population including elderly patients, but the incidence was balanced in both treatment arms. ${ }^{11}$ Serial cognition testing will be performed in PARAGON-HF. ${ }^{63}$ In addition, a dedicated study investigating cognition and PET imaging is planned.
Although clinical trials to date have demonstrated the tolerability of LCZ696, it can be argued that the similar rates of adverse events among LCZ696 and standard therapy may have been the result of patient selection bias. Thus, data from on-going clinical trails and clinical practice are needed to evaluate its long-term efficacy.

\section{Clinical use of LCZ696}

LCZ696 has been approved by the European Medicines Agency ${ }^{72}$ and US Food and Drug Administration ${ }^{73}$ to reduce the risk of cardiovascular death and hospitalisation in adult patients with symptomatic chronic HFrEF. It is usually administered in conjunction with other HF therapies, in place of an ACE inhibitor or an ARB. If switching from an ACE inhibitor, a washout period of 36 hours is important. The recommended starting dose is $49 / 51 \mathrm{mg}$ (sacubitril/valsartan) twice daily. This may be increased after 2-4 weeks to the target maintenance dose of 97/103 mg (sacubitril/ valsartan) twice daily as tolerated by the patient. The starting dose should be reduced to 24/26 mg (sacubitril/valsartan) twice daily for patients not currently taking an ACE inhibitor or an ARB, or previously taking a low dose of these agents, i.e. patients with severe renal impairment (eGFR $<30 \mathrm{ml} / \mathrm{min} / 1.73 \mathrm{~m}^{2}$ ) and patients with moderate hepatic impairment (Child-Pugh B).

\section{Conclusion}

While drugs targeting the RAAS represent the cornerstone of $\mathrm{HF}$ treatment, there is a need for novel therapeutic approaches. LCZ696 is an effective and safe alternative to ACE inhibitors and may change future first-line approaches to HF therapy because of its significant improvement in survival and reduced rates of rehospitalisation. Additionally, LCZ696 has been found more effective than valsartan in hypertensive patients, although comparative studies with other antihypertensive drugs are needed and its effects on cardiovascular outcomes are unknown. Ongoing clinical trials will define its future role in the treatment of HF and other cardiovascular diseases, where ACE inhibitors or ARBs are currently first-line therapies.

For LCZ696 to displace ACE inhibitors and ARBs in daily clinical practice, more information on real-life use of LCZ696 is required, including safety and efficacy in patient groups not included in PARADIGM-HF, i.e. patients with acute decompensated HF and more advanced symptoms (NYHA IV only represented $0.8 \%$ of the study population); elderly and black patients; patients with resistant hypertension, nephropathy and proteinuric renal disease; patients receiving high doses ( $\geq 10 \mathrm{mg}$ twice daily); or treated with ARBs. There is some preliminary evidence of LCZ696 in hypertensive patients with diabetes; furthermore, the benefit of LCZ696 in the PARADIGM-HF trial was reported in 2,907 patients with diabetes. It will also be important to determine which patients will benefit most, for example ACE inhibitor/ARB naive patients, who are commonly encountered in the clinic. For the first time in 30 years, physicians must make a careful therapeutic decision: instead of adding to a drug regimen, they have the option to replace ACE inhibitors or ARBs with LCZ696. This decision should be made with the knowledge that the agent provides proven benefits in terms of reduced mortality and fewer re-hospitalisations.
1. Yancy CW, Jessup M, Bozkurt B, et al. 2013 ACCF/AHA guideline for the management of heart failure: a report of the American College of Cardiology Foundation/American Heart Association Task Force on Practice Guidelines. J Am Coll Cardiol 2013;62:e147-239. DOI: 10.1016/j.jacc.2013.05.019; PMID: 23747642

2. McMurray JJ, Adamopoulos S, Anker SD, et al. ESC Guidelines for the diagnosis and treatment of acute and chronic heart failure 2012. Eur Heart J 2012;33:1787-847. DOI: 10.1093/ eurheartichs104: PMID: 22611136

. Mozaffarian D, Benjamin EJ, Go AS, et al. Heart disease and stroke statistics - 2015 update: a report from the American Heart Association. Circulation 2015;131:e29-322. DOI: 10.1161/ CIR.0000000000000152; PMID: 25520374

4. Stewart S, MacIntyre K, Hole DJ, et al. More "malignant" than cancer? Five-year survival following a first admission for heart failure. Eur J Heart Fail 2001:3:315-22. PMID: 11378002

5. Senni M, Gavazzi A, Oliva F, et al. In-hospital and 1-year
Outcomes of acute heart failure patients according to presentation (de novo vs. worsening) and ejection fraction. Results from IN-HF Outcome Registry. Int I Cardiol 2014;173:163-9. DOI: 10.1016/j.ijcard.2014.02.018; PMID: 24630337

von Lueder TG, Sangaralingham SJ, Wang BH, et al. Reninangiotensin blockade combined with natriuretic peptide system augmentation: novel therapeutic concepts to combat heart failure. Circ Heart Fail 2013;6:594-605. DOI: 10.1161/ 
CIRCHEARTFAILURE.112.000289; PMID: 23694773

Schrier RW, Abdallah JG, Weinberger HH, et al. Therapy of heart failure. Kidney Int 2000:57:1418-25. PMID: 10760077

8. Brewster UC, Setaro JF, Perazella MA. The renin-angiotensinaldosterone system: cardiorenal effects and implications for renal and cardiovascular disease states. Am J Med Sci 2003;326:15-24. PMID: 12861121

9. Lopez-Sendon J, Swedberg K, McMurray J, et al. Expert consensus document on beta-adrenergic receptor blockers. Eur Heart J 2004;25:1341-62. PMID: 15288162

10. McMurray J, Cohen-Solal A, Dietz R, et al. Practical recommendations for the use of ACE inhibitors, betablockers, aldosterone antagonists and angiotensin receptor blockers in heart failure: putting guidelines into practice. Eur Heart Fail 2005:7:710-21. PMID: 16087129

11. CIBIS-II Investigators and Committees. The Cardiac Insufficiency Bisoprolol Study II (CIBIS-II): a randomised trial. Lancet 1999;353:9-13. PMID: 10023943

12. Packer M, Coats AJ, Fowler MB, et al. Effect of carvedilo on survival in severe chronic heart failure. N Engl I Med 2001;344:1651-8. PMID: 11386263

13. MERIT-HF Study Group. Effect of metoprolol CR/XL in chronic heart failure: Metoprolol CR/XL Randomised Intervention Trial in Congestive Heart Failure (MERIT-HF). Lancet 1999:353:2001-7. PMID: 10376614

14. The SOLVD Investigators. Effect of enalapril on survival in patients with reduced left ventricular ejection fractions and congestive heart failure. N Eng/ I Med 1991;325:293-302. PMID: 2057034

15. Pfeffer MA, Swedberg K, Granger CB, et al. Effects of candesartan on mortality and morbidity in patients with chronic heart failure: the CHARM-Overall programme. Lancet 2003:362:759-66. PMID: 13678868

16. Nappi JM, Sieg A. Aldosterone and aldosterone receptor antagonists in patients with chronic heart failure. Vasc Health Risk Manag 2011;7:353-63. DOI: 10.2147/VHRM.S13779; PMID: 21731887

17. Zannad F, McMurray JJ, Krum $\mathrm{H}$, et al. Eplerenone in patients with systolic heart failure and mild symptoms. N Eng/ J Med 2011;364:11-21. DOI: 10.1056/NEJMoa1009492; PMID: 21073363

18. Nobakht N, Kamgar M, Rastogi A, et al. Limitations of angiotensin inhibition. Nat Rev Nephrol 2011:7:356-9. DOl: 10.1038/nrneph.2011.29; PMID: 21502972

19. Bomback AS, Klemmer PJ. The incidence and implications of aldosterone breakthrough. Nat Clin Pract Nephrol 2007:3:48692. PMID. 17717561

20. Sliwa K, Norton GR, Kone N, et al. Impact of initiating carvedilol before angiotensin-converting enzyme inhibitor therapy on cardiac function in newly diagnosed heart failure J Am Coll Cardiol 2004;44:1825-30. PMID: 15519014

21. McMurray JJ, Ostergren J, Swedberg K, et al. Effects of candesartan in patients with chronic heart failure and reduced left-ventricular systolic function taking angiotensinconverting-enzyme inhibitors: the CHARM-Added trial. Lancet 2003:362:767-71. PMID: 13678869

22. Swedberg K, Komajda M, Böhm M, et al. Ivabradine and outcomes in chronic heart failure (SHIFT): a randomised placebo-controlled study. Lancet 2010;376:875-85. DOI: 10.1016/S0140-6736(10)61198-1; PMID: 20801500

23. de Bold AJ, Borenstein HB, Veress AT, et al. A rapid and potent natriuretic response to intravenous injection of atrial myocardia extract in rats. Life Sci 1981;28:89-94. PMID: 7219045

24. Sudoh T, Kangawa K, Minamino N, et al. A new natriuretic peptide in porcine brain. Nature 1988;332:78-81. PMID: 2964562

25. Potter LR, Abbey-Hosch S, Dickey DM. Natriuretic peptides, their receptors, and cyclic guanosine monophosphatedependent signaling functions. Endocr Rev 2006;27:47-72. PMID: 16291870

26. Boerrigter $\mathrm{G}$, Burnett JC Jr. Recent advances in natriuretic peptides in congestive heart failure. Expert Opin Investig Drugs 2004;13:643-52. PMID: 15174950

27. Zois $\mathrm{NE}$, Bartels $\mathrm{ED}$, Hunter I, et al. Natriuretic peptides in cardiometabolic regulation and disease. Nat Rev Cardiol 2014;11:403-12. DOI: 10.1038/nrcardio.2014.64; PMID: 24820868

28. Mangiafico $S$, Costello-Boerrigter LC, Andersen IA, et al. Neutral endopeptidase inhibition and the natriuretic peptide system: an evolving strategy in cardiovascular therapeutics. Eur Heart J 2013;34:886-93c. DOI: 10.1093/eurheartj/ehs262; PMID: 22942338

29. Macheret F, Heublein D, Costello-Boerrigter LC, et al. Human hypertension is characterized by a lack of activation of the antihypertensive cardiac hormones ANP and BNP. J Am Coll Cardiol 2012;60:1558-65. DOI: 10.1016/j.jacc.2012.05.049; PMID: 23058313: PMCID. PMC4041520

30. Forssmann W, Meyer M, Forssmann K. The renal urodilatin system: clinical implications. Cardiovasc Res 2001;51:450-62. PMID: 11476735

31. Ferro CJ, Spratt JC, Haynes WG, et al. Inhibition of neutral endopeptidase causes vasoconstriction of human resistance vessels in vivo. Circulation 1998;97:2323-30. PMID: 9639376

32. Martinez-Rumayor A, Richards AM, Burnett JC, et al. Biology of the natriuretic peptides. Am J Cardiol 2008;101:3-8. DOI: 10.1016/j amicard 2007 11 012. PMID: 18243856

33. Marcus LS, Hart D, Packer M, et al. Hemodynamic and renal excretory effects of human brain natriuretic peptide infusion in patients with congestive heart failure. A double-blind, placebo-controlled, randomized crossover trial. Circulation 1996;94:3184-9. PMID: 8989127

34. O'Connor CM, Starling RC, Hernandez AF, et al. Effect of nesiritide in patients with acute decompensated heart failure. N Engl J Med 2011;365:32-43. DOI: 10.1056/NEJMoa1100171; PMID: 21732835

35. Wang DJ, Dowling TC, Meadows D, et al. Nesiritide does not improve renal function in patients with chronic heart failure and worsening serum creatinine. Circulation 2004;110:1620-5. PMID: 15337695

36. Sackner-Bernstein JD, Kowalski M, Fox M, et al. Shortterm risk of death after treatment with nesiritide for decompensated heart failure: a pooled analysis of randomized controlled trials. JAMA 2005;293:1900-5. PMID: 15840865

37. Sackner-Bernstein JD, Skopicki HA, Aaronson KD. Risk of worsening renal function with nesiritide in patients with acutely decompensated heart failure. Circulation 2005:111:1487-91. PMID. 15781736

38. Chen $\mathrm{HH}$, Burnett JC Jr. Therapeutic potential for existing and novel forms of natriuretic peptides. Heart Fail Clin 2006:2:36573. PMID: 17386905

39. Northridge $D B$, Newby $D E$, Rooney $E$, et al. Comparison of the short-term effects of candoxatril, an orally active neutr endopeptidase inhibitor, and frusemide in the treatment of patients with chronic heart failure. Am Heart J 1999;138:114957. PMID: 10577447

40. Westheim AS, Bostrøm P, Christensen CC, et al. Hemodynamic and neuroendocrine effects for candoxatril and frusemide in mild stable chronic heart failure. J Am Coll Cardiol 1999:34:1794-801. PMID: 10577572

41. Ando S, Rahman MA, Butler GC, et al. Comparison of candoxatril and atrial natriuretic factor in healthy men. Effects on hemodynamics, sympathetic activity, heart rate variability, and endothelin. Hypertension 1995;26:1160-6. DOI 10.1161/01.HYP.26.6.1160

42. Corti R, Burnett JC Jr, Rouleau JL, et al. Vasopeptidase inhibitors: a new therapeutic concept in cardiovascular disease? Circulation 2001;104:1856-62. DOI: 10.1161/ hc4001.097191

43. Margulies KB, Perrella MA, McKinley $L$, et al. Angiotensin inhibition potentiates the renal responses to neutra endopeptidase inhibition in dogs with congestive heart failure. J Clin Invest 1991;88:1636-42. PMID: 1658047; PMCID PMC295690

44. Nathisuwan S, Talbert RL. A review of vasopeptidase inhibitors: a new modality in the treatment of hypertension and chronic heart failure. Pharmacotherapy 2002;22:27-42. PMID: 11794428

45. Packer M, Califf RM, Konstam MA, et al. Comparison of omapatrilat and enalapril in patients with chronic heart failure: the Omapatrilat Versus Enalapril Randomized Trial of Utility in Reducing Events (OVERTURE). Circulation 2002:106:920-6. PMID: 12186794

46. Byrd JB, Touzin K, Sile S, et al. Dipeptidyl peptidase IV in angiotensin-converting enzyme inhibitor associated angioedema, Hypertension 2008;51:141-7. PMID: 18025295 [PubMed - indexed for MEDLINE] PMCID: PMC2749928

47. Messerli FH, Nussberger J, Vasopeptidase inhibition and angio-oedema, Lancet 2000;356:608-9. PMID: 10968427

48. Campbell DJ, Krum H, Esler MD. Losartan increases bradykin levels in hypertensive humans. Circulation 2005;111:315-20. PMID: 15655136

49. Dahlöf B, Devereux RB, Kjeldsen SE, et al. Cardiovascular morbidity and mortality in the Losartan Intervention For Endpoint reduction in hypertension study (LIFE): a randomised trial against atenolol. Lancet 2002;359:995-1003 PMID: 11937178

50. Makani H, Messerli FH, Romero J, et al. Meta-analysis of randomized trials of angioedema as an adverse event of renin-angiotensin system inhibitors. Am J Cardiol 2012;110:383-91. DOI: 10.1016/i.amjcard.2012.03.034; PMID: 22521308

51. Toh $\mathrm{S}$, Reichman $\mathrm{ME}$, Houstoun $\mathrm{M}$, et al. Comparative risk for angioedema associated with the use of drugs that targe the renin-angiotensin-aldosterone system. Arch Intern Med 2012;172:1582-9. DOI: 10.1001/2013.jamainternmed.34; PMID: 23147456

52. Gu J, Noe A, Chandra P, et al. Pharmacokinetics and pharmacodynamics of LCZ696, a novel dual-acting angiotensin receptor-neprilysin inhibitor (ARNi). I Clin Pharmacol 2010;50:401-14. DOl: 10.1177/0091270009343932; PMID: 19934029

53. Packer M, MCMurray JJ, Desai AS, et al. Angiotensin receptor neprilysin inhibition compared with enalapril on the risk of clinical progression in surviving patients with heart failure. Circulation 2015;131:54-61. DOI: 10.1161/ CIRCULATIONAHA.114.013748; PMID: 25403646

54. Kobalava Z, Averkov O, Meray I, et al. Natriuretic peptide nhibition in the presence of angiotensin receptor blockade following short-term treatment with LCZ696 in heart failure patients: effect on ANP, BNP, NT-proBNP and CGMP. Eur Heart 2011:32(Suppl):784-5.

55. Kobalava ZhD, Pavlikova EP, Averkov OA, et al. [First experience of clinical application of LCZ696 - an AT angiotensin receptors and neprilysin inhibitor - in patients with chronic heart failure and reduced ejection fraction]. Kardiologiia 2015;55:14-25.

56. Desai AS, McMurray JJ, Packer M, et al. Effect of the angiotensin-receptor-neprilysin inhibitor LCZ696 compared with enalapril on mode of death in heart failure patients. EUr Heart J 2015;36:1990-7. DOI: 10.1093/eurheartj/ehv186; PMID: 26022006

57. McMurray JJ, Packer M, Desai AS, et al. Angiotensin-neprilysin inhibition versus enalapril in heart failure. $N$ Engl I Med 2014;371:993-1004. DOI: 10.1056/NEJMoa1409077; PMID: 25176015

58. Claggett B, Packer M, McMurray JJ, et al. Estimating the long-term treatment benefits of sacubitril-valsartan. N Eng/ Med 2015;373:2289-90. DOI: 10.1056/NEJMC1509753; PMID: 26630151

59. Kristensen SL, Preiss D, Jhund PS, et al. Risk related to pre-diabetes mellitus and diabetes mellitus in heart failure with reduced ejection fraction: insights from prospective comparison of ARNI With ACEI to determine impact on global mortality and morbidity in heart failure trial. Circ Heart Fail 2016;9:pii: e002560. DOI: 10.1161/ CIRCHEARTFAILURE.115.002560; PMID: 26754626; PMCID: PMC4718182

60. Senni M, Reyes A, Majercak I, et al. Results of the TITRATION study: A 12-week, multicentre, randomized, double-blind, safety evaluation of a 3-versus 6-week up-titration regimen of LCZ696 in patients with HFrEF. Presented at Heart Failure 2015, Seville, Spain, 23-26 May 2015. Presentation 44.

61. Solomon SD, Zile M, Pieske B, et al. The angiotensin receptor neprilysin inhibitor LCZ696 in heart failure with preserved ejection fraction: a phase 2 double-blind randomised controlled trial. Lancet 2012;380:1387-95. DOI: 10.1016/S01406736(12)61227-6; PMID: 22932717

62. Voors AA, Gori M, Liu LC, et al. Renal effects of the angiotensin receptor neprilysin inhibitor LCZ696 in patients with heart failure and preserved ejection fraction. Eur $\mathrm{H}$ Heart Fail 2015;17:510-7. DOI: 10.1002/ejhf.232; PMID: 25657064

63. NCT01920711, Efficacy and Safety of LCZ696 Compared to Valsartan, on Morbidity and Mortality in Heart Failure Patients With Preserved Ejection Fraction (PARAGON-HF). Available at: https://clinicaltrials.gov/ct2/show/NCT01920711 (3 November 2015).

64. Ruilope LM, Dukat A, Böhm M, et al. Blood-pressure reduction with LCZ696, a novel dual-acting inhibitor of the angiotensin receptor and neprilysin: a randomised, double-blind, placebocontrolled, active comparator study. Lancet 2010;375:1255-66. DOI: 10.1016/S0140-6736(09)61966-8; PMID: 20236700

65. Kario K, Sun N, Chiang FT, et al. Efficacy and safety of LCZ696, a first-in-class angiotensin receptor neprilysin inhibitor, in Asian patients with hypertension: a randomized, doubleblind, placebo-controlled study. Hypertension 2014;63:698-705. DOI: 10.1161/HYPERTENSIONAHA.113.02002; PMID: 24446062

66. Brown NJ, Ray WA, Snowden M, et al. Black Americans have an increased rate of angiotensin converting enzyme inhibitorassociated angioedema. Clin Pharmacol Ther 1996;60:8-13. PMID: 8689816

67. Gibbs CR, Lip GY, Beevers DG. Angioedema due to ACE inhibitors: increased risk in patients of African origin. Br J Clin Pharmacol 1999:48:861-5. PMID: 10594491

68. Vodovar N, Paquet C, Mebazaa A, et al. Neprilysin, cardiovascular, and Alzheimer's diseases: the therapeutic split? Eur Heart J 2015;36:902-5. DOI: 10.1093/eurheartj/ ehv015; PMID: 25636748

69. Fu Y, Li AF, Shi JJ, et al. Lack of association of neprilysin gene polymorphisms with Alzheimer's disease in a southern Chinese community. Int Psychogeriatr 2009;21:354-8. DOI: 10.1017/S1041610208008338; PMID: 19250583

70. Langenickel TH, Tsubouchi C, Ayalasomayajula S, et al. The effect of LCZ696 on amyloid-beta concentrations in cerebrospinal fluid in healthy subjects, Br I Clin Pharmacol 2015: PMID: 26663387: epub ahead of print.

71. Cannon J, Boytsov S, Senni M, et al. Dementia-related adverse effects in the prospective comparison of ARNI with ACEI to determine impact on global mortality and morbidity in heart failure trial (PARADIGM-HF). European Journal of Heart Failure 2015; 17(Suppl):49-50

72. EMA, New medicine to treat heart failure recommended for approval. Available at: http://www.ema.europa.eu/ema/index. jsp?curl=pages/news_and_events/news/2015/09/news_ detail_002401.jsp\&mid=WCOb01ac058004d5c1 (accessed 30 December 2015).

73. FDA. FDA approves new drug to treat heart failure. Available at: www.fda.gov/NewsEvents/Newsroom PressAnnouncements/ucm453845.htm (30 December 2015).

74. ISRCTN registry. UK Heart and Renal Protection (UK HARP-III). Available at: http://www.isrctn.com/ISRCTN11958993 (30 December 2015) 